\title{
Reflexiones sobre la carencia de especialistas
}

\section{Considerations regarding the shortage of specialists}

Recientemente un titular de "El Mercurio" denunciaba que hacen falta 1.700 especialistas en el Sistema Nacional de Servicios de Salud.

Es probable que falten muchos más dado que no todos trabajan jornadas completas y las necesidades van en aumento debido al constante progreso de la medicina y la tecnología y al aumento de edad de la población que modifica e incrementa las patologías prevalentes.

¿A que se debe este grave problema que se suma a otras carencias importantes en nuestra sociedad, como se ha manifestado recientemente?

Primero, hay mala distribución de médicos ya que no existen adecuados incentivos para atraerlos a las regiones en falencia. Estos no son sólo económicos (que es muy importante) sino que de calidad de vida. Lugares donde educar bien a sus hijos, puestos de trabajo para sus cónyuges, nivel de infraestructura tecnológica para ejercer la medicina con el grado de desarrollo actual, posibilidades de progreso médico atractivo, entre otros.

También hay falta de cupos en los programas de formación acreditados y el costo actual de estos mismos los hace dificil de solventar para muchos médicos que desean postular. La Universidad Católica de Chile es actualmente la única institución universitaria acreditada que otorga a todos sus alumnos de postítulo un estipendio que les permite tener dedicación exclusiva. Esto es fundamental para obtener una formación adecuada y al mismo tiempo tener una vida de calidad, con tiempo para estudiar, para la familia y el normal esparcimiento. Es cierto que el Servicio de Salud Pública también otorga un sueldo a sus médicos en programas de retorno, e incluso en becas primarias, pero esto es claramente insuficiente. El número de especialistas que logran formarse en estos cupos no han disminuido la brecha de especialistas que trabajan en el sistema privado y el público, lo cual se traduce en las largas listas de espera para interconsultas especializadas y para procedimientos quirúrgicos complejos como cirugía cardíaca, entre otras. El número de cirugías cardíacas en nuestro país por millón de habitantes es el más bajo de los países del OCDE.

Falta estimular a las universidades a crear nuevos programas de formación de calidad y acreditables en las áreas de falencia. Sin embargo, debemos enfatizar que no sólo interesa el número de especialistas, sino que hay necesidad de reforzar la formación ética de los cirujanos y de los médicos en general. Esto es muy relevante en aquellos que se dedican a realizar procedimientos invasivos, para que antepongan los intereses del paciente por encima de los intereses personales o de las instituciones donde trabajan. Por otro lado, los desafios que plantea la sociedad, como el llamado “aborto terapéutico”, la eutanasia, las terapias génicas, los trasplantes de múltiples órganos, entre otros, han gatillado un renovado interés por definir nuevos estándares éticos. Los cirujanos necesitan una fuerte formación moral como base para enfrentar estos desafios. El liderazgo que deben ejercer implica guiar a su equipo con el ejemplo. Por eso es tan importante que las instituciones que forman a los futuros especialistas quirúrgicos tengan la complejidad y los docentes que los guien en un ambiente donde se estimule el comportamiento ético y se supervise la conducta personal y grupal. Esto incluye desde la delicada relación médico-paciente, las relaciones con el equipo de trabajo y formas de enfrentar el estrés.

Es primordial para el buen desarrollo de nuestra medicina, contar con académicos de experiencia e idoneidad en estos aspectos, que formen parte de los docentes de los programas de postítulo para asi actuar de modelo e inspirar a las nuevas generaciones. Esto es esencial que se cumpla para que un programa sea acreditado. No basta con un currículo que incluya las materias propias de la especialidad. Sólo asi caminaremos hacia la solución efectiva de las carencias de especialistas en el sistema público que nos preocupa. 
EDITORIAL

La experiencia que he adquirido en ÁPICE/Chile me ha señalado que esta falta de académicos calificados es un problema real en la actualidad y que debe abordarse con prontitud.

Por otro lado, la medicina y en especial la cirugía y sus sub especialidades están en constante progreso, nuevos conocimientos en ciencias básicas y aplicadas permiten nuevas operaciones y tratamientos cada vez más complejos que requieren de más especialistas idóneos. Por eso es probable que siempre haya un equilibrio inestable entre oferta y demanda de especialistas, problema que se observa no sólo en Chile, sino que en el resto del mundo aunque con grados diversos de gravedad.

Para ayudar a encontrar soluciones a este problema, propongo que se busque financiamiento para todos los alumnos de postitulo entre las fundaciones educacionales del país, el ministerio de salud, las universidades que deseen contribuir al desarrollo nacional y al mismo tiempo estimular y facilitar las donaciones de las empresas relacionadas a la salud y las grandes empresas nacionales.

Apoyo del ministerio de educación y de las otras instituciones mencionadas arriba, a los centros formadores acreditados para la adquisición de infraestructura tecnológica para la docencia, como simuladores para ensayar procedimientos invasivos complejos y de riesgo para los pacientes. Laboratorios de cirugía experimental para realizar enseñanza de técnicas complejas y desarrollar nuevas operaciones e investigar nuevos métodos.

Aumento de vacantes de especialidades en falencia e incentivos adecuados para atraer a los especialistas que tanto se necesitan en regiones.

Estímulo a la creación de nuevos centros de excelencia en regiones y facilitar que los pacientes puedan ser atendidos en los centros ya existentes que tienen capacidad para ello y no los ocupan actualmente. Aprovechar toda la infraestructura nacional de salud, ya sean hospitales públicos, universitarios, de las FF.AA. o privados.

Se hace necesario un estudio para saber realmente cuantos especialistas se requieren hoy, a cinco, diez $y$ veinte años para planear mejor como obtener recursos humanos médicos y de otros profesionales de la salud. Los resultados deben ser difundidos para orientar a los alumnos a tomar sus decisiones profesionales conociendo donde se les necesita y donde están sus posibilidades de trabajo y desarrollo personal para bien del pais.

Prof. Dr. Sergio Morán $\boldsymbol{V}$. Pontificia Universidad Católica de Chile Santiago, Chile sergio.moranv@gmail.com 